\title{
EFFECTS OF AN EIGHT-MONTH EXERCISE INTERVENTION PROGRAMME ON PHYSICAL ACTIVITY AND DECREASE OF ANXIETY IN ELEMENTARY SCHOOL CHILDREN
}

\author{
Irina Klizienè $\dot{1}^{1}$, Laura Kimantiené ${ }^{1}$, Ginas Čižauskas ${ }^{1}$, \\ Giedrè Marcinkevičiūtė $\dot{1}^{1}$, Viktorija Treigyt $\dot{e}^{2}$ \\ Kaunas University of Technology ${ }^{\prime}$, Kaunas, Lithuania \\ Lithuanian Sports University', Kaunas, Lithuania
}

\begin{abstract}
Background. The World Health Organization recommends children to participate in sufficient PA by engaging in moderate-to-vigorous physical activity for at least 60 min daily per week. Schools are important settings for the promotion of children's physical activity. Through commuting, breaks, and physical education lessons they provide regular opportunities for children to be active.

Methods. The experimental group included 36 girls and 34 boys aged 6-7 years old. Their mean weight and height were $24.3 \pm 0.9 \mathrm{~kg}$ and $1.25 \pm 0.11 \mathrm{~m}$ for the girls, and $29.3 \pm 0.6 \mathrm{~kg}$ and $1.33 \pm 0.09 \mathrm{~m}$ for the boys. The control group included 35 girls and 33 boys aged 6-7 years old, attending the same school. Their mean weight and height were $22.3 \pm 0.7 \mathrm{~kg}$ and $1.24 \pm 0.1 \mathrm{~m}$ for the girls, and $28.4 \pm 0.7 \mathrm{~kg}$ and $1.36 \pm 0.07 \mathrm{~m}$ for the boys. The methodology of innovative physical education classes was based on the DIDSFA model (dynamic exercise, intense motor skill repetition, differentiation, physical activity distribution in the classroom). The evaluation of physical activity. Children's Physical Activity Questionnaire (Corder et al., 2009) was used. It was also based on the Children's Leisure Activities Study Survey (CLASS) questionnaire. The measurement of anxiety - the methodology of Reynolds and Richmond (1994).

Results. The post-test of the experimental group boys (1320.24 MET, min/week) was to analyse average physical activity in comparison with the girls of the experimental group (840.60 MET, min/week). Statistically significant difference was found during the analysis of average MET per boy (1390.45 MET, min/week) in comparison with the girls $(880.27 \mathrm{MET}$, min/week, $p<.05)$. The results of the somatic anxiety in EG $(5.54 \pm 1.18$ points $)$ before the experiment and after it showed that after the intervention programme somatic anxiety in EG was $5.08 \pm 1.09$ points. This demonstrates lower levels of depression, seclusion, somatic complaints, aggression and delinquent behaviour $(F=4.895, p<.05, \mathrm{P}=0.550)$.

Conclusion. It was established that properly construed and purposefully applied complex of the eight-month exercise intervention programme for elementary school children led to statistically significant changes in the dependent variables: increased physical activity and decreased anxiety for the experimental group.
\end{abstract}

Keywords: physical activity, anxiety, innovative physical education classes, primary education.

\section{INTRODUCTION}

$\mathrm{R}$ esearch has shown that participation in school physical education (PE) may affect students' motivation to engage in physical activity because it has the potential to provide both positive and negative experiences for the student population (McKenzie, 2007). Schools are an ideal setting to implement physical activity programs targeted at youths' learning and intellectual abilities. Physical inactivity has been identified as an independent risk factor for coronary heart disease (CHD) with the risk for CHD increased nearly twofold for persons who are physically inactive (Berlin \& Colditz, 1990). Reports have attributed $22-30 \%$ of cardiovascular deaths, 20 
$60 \%$ of cancer deaths, and $30 \%$ of diabetes deaths to sedentary lifestyles and dietary factors (McGinnis \& Foege, 1993), given that physical inactivity is a pervasive problem causing both critical health issues and placing a huge cost on global economy (Finkelstein, Trogdon, Cohen, \& Dietz, 2009). When children experience positive outcomes from their involvement in physical activity, they can also be expected to remain involved in physical activity in adulthood (Dishman et al., 2005).

Physical activity and exercise have positive effects on mood and anxiety and a great number of studies describe an association of physical activity and general well-being, mood and anxiety (Ströhle, 2009). Physical inactivity may also be associated with the development of mental disorders: some clinical and epidemiological studies have shown associations between physical activity and symptoms of depression and anxiety in cross-sectional and prospective-longitudinal studies (Abu-Omar, Rütten, \& Lehtinen, 2004). Although physical education lessons are often seen as funny and enjoyable, they may also trigger negative feelings such as anxiety because of their comparative, competitive and evaluative nature (Barkoukis, Tsirbatzoudis, Grouios, \& Rodafinos, 2005). Anxiety in physical education classes can be manifested through cognitive (e.g. negative thoughts), bodily (e.g. alteration in muscle tension), and information processing (e.g. worry and attention disruption) symptoms (Barkoukis et al., 2005). On other hand, low physical activity levels are associated with increased prevalence of anxiety (Stubbs et al., 2017).

The purpose of this study was to establish the effects of a 8-month exercise intervention programme on physical activity and decrease of anxiety for first grade students

\section{METHODS}

Participants. According to the SVIS data base statistics (http://www.svis.smm.lt/), the number of first grade students in year 2017/2018 was 30.126 in total (14.609 of girls). All in all, 384 first form students had to be tested. This study was only observational and therefore a smaller number of respondents were selected.

The school was randomly selected from primary schools in Lithuania. With the approval of the parents, the time and place of the examination were agreed with the school administration in advance. The study took place in 2017 from September to November in four Lithuanian general education schools that had primary education and primary education classes. The time and place of the study, with the consent of the parents, were agreed upon in advance with the school administration.

The experimental group included 36 girls 34 boys aged 6-7 years old. Their mean weight and height were $24.3 \pm 0.9 \mathrm{~kg}$ and $1.25 \pm 0.11 \mathrm{~m}$ for the girls, and $29.3 \pm 0.6 \mathrm{~kg}$ and $1.33 \pm 0.09 \mathrm{~m}$ for the boys. The control group included 35 girls and 33 boys aged 6-7 years old, attending the same school. Their mean weight and height were $22.3 \pm 0.7 \mathrm{~kg}$ and $1.24 \pm 0.1 \mathrm{~m}$ for the girls, and $28.4 \pm 0.7 \mathrm{~kg}$ and $1.36 \pm 0.07 \mathrm{~m}$ for the boys.

In the present research, we used a pre-test/ post-test experimental strategy, which was chosen to avoid any interference with educational activities due to the random selection of children into the groups. The experimental group was under test during eight months. We developed the methodology of innovative physical education classes and created the model of educational factors stimulating pupils' physical activity. We identified relationships between the pupils' physical activities at school and learning achievements. We also prepared the methodical material for innovative physical education classes. The methodology was based on the DIDSFA model (dynamic exercise, intense motor skills repetition, differentiation, reduction of parking and seating, physical activity distribution in the classroom) (Powell, Woodfield, \& Nevill, 2016; Buliuolienè, Daukšaite, Klizas, Klizienè, \& Cibulskas, 2017). The girls and boys in the control group attended the same (non-modified) physical education lessons.

The evaluation of physical activity. Children's Physical Activity Questionnaire (Corder et al., 2009) was used. It was also based on the Children's Leisure Activities Study Survey (CLASS) questionnaire, which included activities specific to young children, such as "playing in a playhouse." The original intent of the proxy-reported CLASS questionnaire for 6-7-year-olds was to assess type, frequency, and intensity of physical activity over a usual week.

The evaluation of children's anxiety. The methodology of Reynolds and Richmond (1994) was used (Dewaraja Sato, \& Ogawa, 2006; Klizienè, Klizas, Čižauskas, \& Sipavičienè, 2018). The Revised Children's Manifest Anxiety Scale (RCMAS) contains 37 items with 28 items used to measure anxiety and an additional nine items that present an index of the child's level of defensiveness. For our study, we were only concerned about the factor analysis of anxiety; therefore, only those 28 items used to measure anxiety were used in this factorial analysis. The RCMAS consists of three factors, 1) somatic anxiety consisting of 12 items, 2) personality anxiety consisting of eight items, 
and 3) social anxiety consisting of eight items. The results are estimated as follows: 1) somatic anxiety (up to 6.0 points - high somatic level, from 5.9 to 4.5 points - average somatic level, from 4.4 to 1.0 point low somatic level); 2) personality anxiety (from 2.0 to 2.5 points - low personality anxiety level, from 2.6 to 3.5 points - average personality anxiety level, from 3.6 to 4.5 points - high personality anxiety level); and 3) social anxiety (to 5.5 points - high social anxiety level, from 5.4 to 4.5 points - average social anxiety level, from 4.4 to 3.3 points - low social anxiety level). Cronbach's alpha coefficient for subscales ranged from .72-.73.

Mathematical statistics. The arithmetic mean (x) and the average standard deviation (SD) were determined for comparison. Differences between different genders, age and physical fitness were estimated using one-factor dispersion analysis (ANOVA). The relationship between variables was calculated on the basis of the correlation coefficient of the Spearman correlation coefficient. Differences between different genders and physical activity were estimated using Mann-Whitney $U$ test. The following reliability levels were used for statistical outputs: $p>.05$ - insignificant; $p<.05-$ significant. All calculations were performed using MS Excel and SPSS programs.

\section{RESULTS}

Physical activity of 7-year-old children. On analysing the pre-test results of physical activity of the 7-year-old students, it turned out that both the boys (115.05MET, min/week) and girls (90.58 MET, $\mathrm{min}$ (week) in the experimental group were physically active during physical education classes $(p>.05)$.

The analysis of physical activity types, such as cycling to school and walking to school showed that there were no differences in gender according to MET. In the context of average physical activity,

Table 1. Physical activity level using the MET method (the pre-test/post-test results of the experimental group)

\begin{tabular}{|c|c|c|c|c|}
\hline Type of physical activity & MET & $1 \mathrm{day} / \mathrm{min}$ & Days per week & MET (min/week) \\
\hline \multicolumn{5}{|c|}{ The experimental group pre-test } \\
\hline \multicolumn{5}{|c|}{ Boys } \\
\hline Physical education lesson & 3.5 & 30 & 1 & 87.90 \\
\hline Cycling to school & 4 & 0.6 & 3 & 20.54 \\
\hline Walking to school & 3.3 & 0 & 4 & 0.00 \\
\hline Sports groups (mean physical activity) & 6 & 56 & 1 & 1053.84 \\
\hline \multicolumn{4}{|c|}{ On average for one boy } & $1162.28 *$ \\
\hline \multicolumn{5}{|c|}{ Girls } \\
\hline Physical education lesson & 3.5 & 30 & 1 & 81.58 \\
\hline Cycling to school & 4 & 0.36 & 3 & 16.75 \\
\hline Walking to school & 3.3 & 0.85 & 4 & 2.50 \\
\hline Sports groups (mean physical activity) & 6 & 56 & 1 & 652.11 \\
\hline \multicolumn{4}{|c|}{ On average for one girl } & $773.94 *$ \\
\hline \multicolumn{5}{|c|}{ Experimental group post-test } \\
\hline \multicolumn{5}{|c|}{ Boys } \\
\hline Physical education lesson & 3.5 & 30 & 1 & 115.05 \\
\hline Cycling to school & 4 & 0.6 & 3 & 19.68 \\
\hline Walking to school & 3.3 & 0 & 4 & 0.00 \\
\hline Sports groups (mean physical activity) & 6 & 56 & 1 & 1185.51 \\
\hline \multicolumn{4}{|c|}{ On average for one boy } & $1320.24 *$ \\
\hline \multicolumn{5}{|c|}{ Girls } \\
\hline Physical education lesson & 3.5 & 30 & 1 & 90.58 \\
\hline Cycling to school & 4 & 0.36 & 3 & 17.50 \\
\hline Walking to school & 3.3 & 0.85 & 4 & 25.14 \\
\hline Sports groups (mean physical activity) & 6 & 56 & 1 & 707.38 \\
\hline \multicolumn{4}{|c|}{ On average for one girl } & $840.60 *$ \\
\hline
\end{tabular}

Note. $* p<.05$ (according to the Mann-Whitney $U$ test). 
a higher indicator (1053.84 MET, min/week) was detected in the boys of the experimental group in comparison with the girls (652.11 MET, min/week). Statistically significant differences were found in average MET per boy (1162.28 MET, min/week) in comparison with the girls (773.94 MET, min/week) $(p<.05$, Table 1$)$.

The post-test of the experimental group boys (1185.51 MET, min/week) was to analyse average physical activity in comparison with the girls of the experimental group (707.38 MET, $\mathrm{min} /$ week). Statistically significant difference was found during the analysis of average MET per boy (1320.24 MET, min/week) in comparison with the girls (840.60 MET, min/week, $p<.05$; Table 1).

Analysing the results of the 7-year-old students' physical activity, it turned out that in the control group, both boys (92.36 MET, min/week) and girls (90.15 MET, min/week) were physically active in physical education classes $(p>.05)$ during the pre-test.

The analysis of physical activity types such as cycling to school and walking to school found no differences in gender according to MET. A higher number of the boys in the control group (938.16 MET, min/week) was determined during the analysis of average physical activity compared to the girls of the same group (558.24 MET, min/ week). Statistically significant differences were found during the analysis of average MET per boy in the control group (1048.76 MET, min/week) compared to the girls (678.59 MET, min/week, $p<.05$; Table 2).

The post-test results of the boys of the control group (1000.98 MET, min/week) were determined by the analysis of average physical activity in

Table 2. Physical activity level using the MET method (the pre-test/post-test results of the control group)

\begin{tabular}{|c|c|c|c|c|}
\hline Type of physical activity & MET & $1 \mathrm{day} / \mathrm{min}$ & Days per week & MET (min/week) \\
\hline \multicolumn{5}{|c|}{ Control group pre-test } \\
\hline \multicolumn{5}{|c|}{ Boys } \\
\hline Physical education lesson & 3.5 & 30 & 1 & 90.36 \\
\hline Cycling to school & 4 & 0.80 & 3 & 21.18 \\
\hline Walking to school & 3.3 & 0 & 4 & 0.00 \\
\hline Sports groups (mean physical activity) & 6 & 56 & 1 & 938.16 \\
\hline \multicolumn{4}{|c|}{ On average for one boy } & $1048.70 *$ \\
\hline \multicolumn{5}{|c|}{ Girls } \\
\hline Physical education lesson & 3.5 & 30 & 1 & 88.34 \\
\hline Cycling to school & 4 & 0.41 & 3 & 11.88 \\
\hline Walking to school & 3.3 & 0.48 & 4 & 20.13 \\
\hline Sports groups (mean physical activity) & 6 & 56 & 1 & 558.24 \\
\hline \multicolumn{4}{|c|}{ On average for one girl } & $678.59^{*}$ \\
\hline \multicolumn{5}{|c|}{ Control group post-test } \\
\hline \multicolumn{5}{|c|}{ Boys } \\
\hline Physical education lesson & 3.5 & 30 & 1 & 92.08 \\
\hline Cycling to school & 4 & 0.80 & 3 & 24.10 \\
\hline Walking to school & 3.3 & 0 & 4 & 0.00 \\
\hline Sports groups (mean physical activity) & 6 & 56 & 1 & 1000.98 \\
\hline \multicolumn{4}{|c|}{ On average for one boy } & $1117.16^{*}$ \\
\hline \multicolumn{5}{|c|}{ Girls } \\
\hline Physical education lesson & 3.5 & 30 & 1 & 90.15 \\
\hline Cycling to school & 4 & 0.41 & 3 & 12.56 \\
\hline Walking to school & 3.3 & 0.48 & 4 & 20.23 \\
\hline Sports groups (man physical activity) & 6 & 56 & 1 & 585.09 \\
\hline \multicolumn{4}{|c|}{ On average for one girl } & $708.03 *$ \\
\hline
\end{tabular}

Note. ${ }^{*} p<.05$ (according to Mann-Whitney $U$ test). 


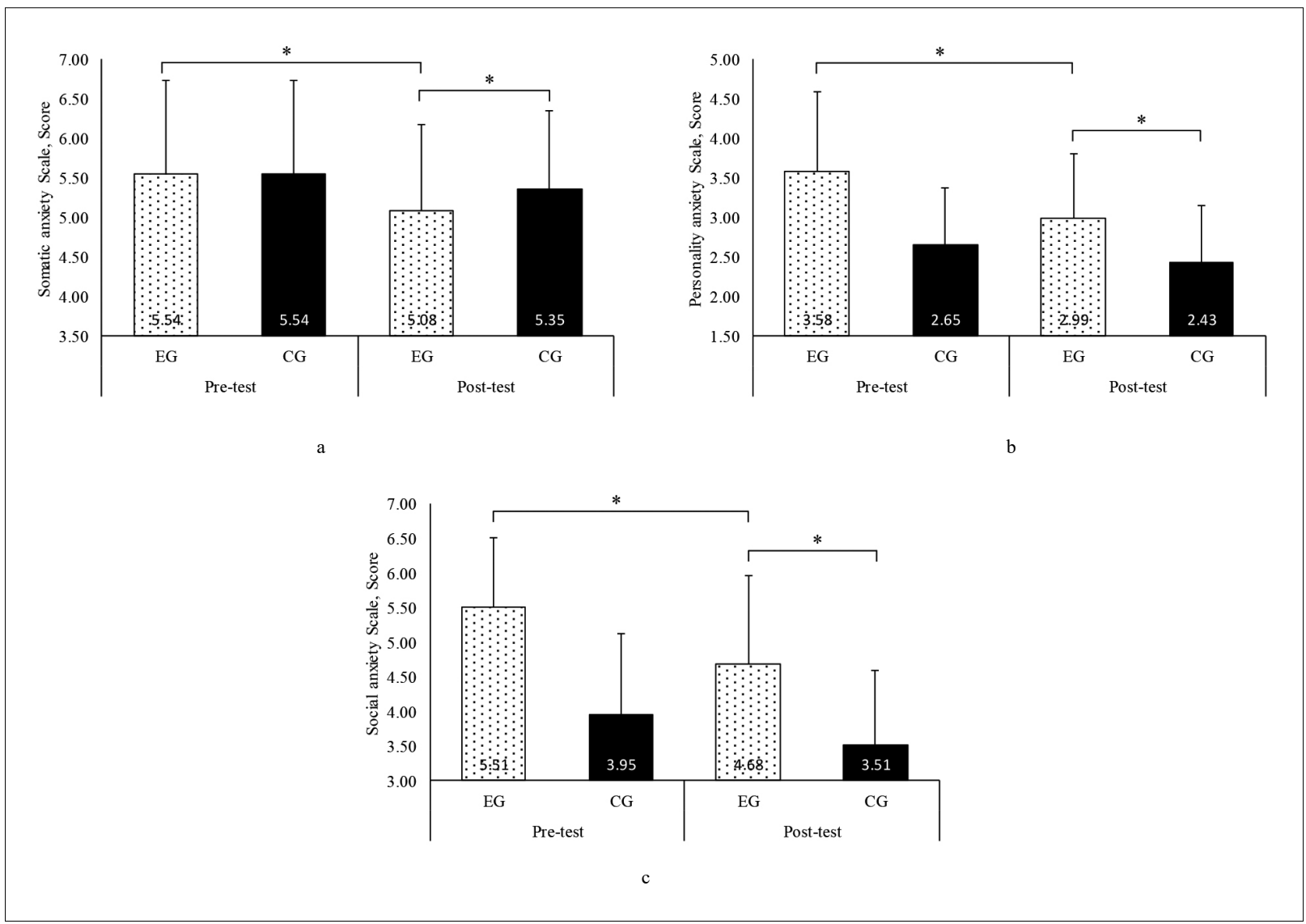

Figure. The level of elementary school children's somatic anxiety (a), personality anxiety (b), and social anxiety (c) in the pre-test and post-test

comparison with the girls of the same group (585.09 MET, min/week). Statistically significant differences were found in average MET per boy (1117.16 MET, min/week) in comparison with the girls (708.03 MET, min/week, $p<.05$, Table 2).

Anxiety of 7-year-old children. The study performed at the beginning of the experiment showed that in the pre-test, the level of somatic anxiety of the adolescents in CG (girls and boys) was average (5.54 \pm 1.18 points). When exploring the results of the somatic anxiety in EG (5.54 \pm 1.18 points) before the experiment and after it, we established that after the intervention programme, somatic anxiety in EG was $5.08 \pm 1.09$ points. This demonstrates lower levels of depression, seclusion, somatic complaints, aggression and delinquent behaviour ( $\mathrm{F}=4.895, p<.05, \mathrm{P}=0.550$; Figure a).

When dealing with the results of the anxiety of personality, we established that in pre-test and posttest, the results of CG students were not statistically significantly different $(2.65 \pm 0.73$ points and $2.43 \pm$ 0.73 points correspondingly, $\mathrm{F}=0.138, p>.05$, $\mathrm{P}=0.048)$. When analysing EG personality anxiety results in pre-test and post-test, we established that after the intervention programme, EG personality anxiety results decreased $(3.58 \pm 1.00$ points and $2.299 \pm 0.82$ points correspondingly, $\mathrm{F}=5.205$, $p<.05, \mathrm{P}=0.598$; Figure b).

In the pre-test, the level of social anxiety in CG was $3.95 \pm 1.18$ points. The post-test $C G$ result was statistically significantly lower $(3.51 \pm 1.09$ points, $\mathrm{F}=3.265, p<.05, \mathrm{P}=0.667)$. When analysing the levels of the social anxiety of EG, pre-test and post-test results decreased after the intervention programme $(5.51 \pm 1.00$ points and $4.68 \pm 1.27$ points correspondingly) and were significantly different $(\mathrm{F}=7.038, p<.05, \mathrm{P}=0.698$; Figure $\mathrm{c})$.

\section{DISCUSSION}

It was established that the properly construed and purposefully applied complex of the eightmonth exercise intervention programme for first grade students led to the statistically significant changes in the dependent variables: increased physical activity and decreased anxiety for the experimental group.

The main aim of this research was to evaluate a one-year teaching strategy intervention, which supported teachers in increasing children's active 
learning time during primary physical education classes. Our results indicated that the intervention programme was effective. The goal of a positive youth development perspective is the promotion of healthy physical and psychosocial development in young people. School physical education represents a context that has the potential for promoting positive youth development by helping students acquire life skills and psychosocial as well as behavioural attributes that can transfer to other important domains (school, family, work) concurrently and over the life span (Weiss, 2012). Physical activity has potentially beneficial effects for reduced depression, but the evidence base is limited. Intervention designs are low in quality, and many reviews include cross-sectional studies. Physical activity interventions have been shown to have a small beneficial effect for reduced anxiety, but the evidence base is limited. Physical activity can lead to improvements in self-esteem, at least in the short term (Biddle \& Asare, 2011). Strauss, Rodzilsky, Burack, and Colin (2001) found that children spent $75.5 \%$ of the day inactive, with a mean $\pm S D$ of $5.2 \pm 1.8$ hours watching television, sitting at the computer, and doing homework. In contrast, only $1.4 \%$ of the day (12.6 \pm 12.2 minutes) was spent in vigorous activity. Time spent in sedentary behaviours was inversely correlated with the amount of moderatelevel activity $(p<.001)$ but not high-level activity. High-level physical activity was also associated with improved self-esteem $(p<.05)$ (Strauss et al., 2001). Yoo et al. (2016) analysed the effects of a school-based mind subtraction meditation program on depression, social anxiety, aggression levels of 42 elementary school children in South Korea. The research design was a non-equivalent group comparison with pre-test and post-test. The experimental group was given eight weeks of the meditation program. The results showed social anxiety, aggression levels were significantly lowered in the experimental group. This demonstrated that the school-based mind subtraction meditation program could be effective in improving psychosocial and behavioural aspects of mental health in elementary school children. Hollis et al. (2016) found, that the percentage of physical education (PE) lesson time spent in PA ranged between 11.4-88.5\%. When measured using direct observation and accelerometers, children spent $57.6(47.3-68.2)$ and 32.6 (5.9$59.3) \%$ of PE lesson time in PA, respectively. In our study, we found the same results of both boys and girls being physically active in physical education lessons $(p<.05)$.

\section{CONCLUSION}

It was established that properly construed and purposefully applied complex of the eight-month exercise intervention programme for elementary school children led to the statistically significant changes in the dependent variables: increased physical activity and physical fitness in the experimental group.

\section{REFERENCES}

Abu-Omar, K., Rütten, A., \& Lehtinen, V. (2004). Mental health and physical activity in the European Union. Soz Praventivmed, 49, 301-309.

Barkoukis, V., Tsirbatzoudis, A., Grouios, G., \& Rodafinos A. (2005). The development of a physical education state anxiety scale: A preliminary study. Perceptual \& Motor Skills, 100, 118-128. https://doi. org/10.2466/pms.100.1.118-128

Berlin, J. A., \& Colditz, G. A. (1990). A meta-analysis of physical activity in the prevention of coronary heart disease. American Journal of Epidemiology, 132, 612618 .

Biddle, S. J. H, \& Asare, M. (2011). Physical activity and mental health in children and adolescents: A review of reviews. British Journal of Sports Medicine, 45(11), http://dx.doi.org/10.1136/bjsports-2011-090185
Buliuolienė, L., Daukšaitè, L., Klizas, Š., Klizienè, I., \& Cibulskas, G. (2017). Küno kultūra: mokytojo knyga 2 klasei. Kaunas: Šviesa.

Corder, K., van Sluijs, E. M., Wright, A., Whincup, P., Wareham, N. J., \& Ekelund, U. (2009). Is it possible to assess free-living physical activity and energy expenditure in young people by self-report? The American Journal of Clinical Nutrition, 89(3), 862-870. https://doi.org/10.3945/ajen.2008.26739

Dewaraja, R., Sato, H., \& Ogawa, T. (2006). Anxiety in tsunami-affected children in Sri Lanka measured by revised children's manifest anxiety scale and synthetic house-tree-person test. International Congress Series, 1287, 74-78. doi: 10.1016/j.ics.2005.12.035

Dishman, R. K., Motl, R. W., Saunders, R., Felton, G., Ward, D. S., \& Pate, R. R. (2005). Enjoyment mediates 
the effects of a school-based physical activity intervention among adolescent girls. Medicine and Science in Sports and Exercise, 37, 478-487.

Finkelstein, E.A., Trogdon, J. G., Cohen, J. W., \& Dietz, W. (2009). Annual medical spending attributable to obesity: Payer- and service-specific estimates. Health Affairs, 8, 822-831. doi: 10.1377/hlthaff.28.5.w822.

Hollis, J. L., Williams, A. J., Sutherland, R., Campbell, E., Nathan, N., Wolfenden, L., ... Wiggers, J. (2016). A systematic review and meta-analysis of moderate-tovigorous physical activity levels in elementary school physical education lessons. Preventive Medicine, 86, 34-54. https://doi.org/10.1016/j.ypmed.2015.11.018

McGinnis, J. M., \& Foege, W. H. (1993). Actual causes of death in the U.S. Journal of the American Medical Association, 270, 2207-2212.

McKenzie, T. L. (2007). The preparation of physical educators: A public health perspective. Quest, 59, 346-357.

Klizienè, I., Klizas, Š., Čižauskas, G., \& Sipavičienė, S. (2018). Effects of a 7-month exercise intervention programme on the psychosocial adjustment and decrease of anxiety among adolescents. European Journal of Contemporary Education, 7(1), 127-136.

Powell, E., Woodfield, L. A., \& Nevill, A. M. (2016). Increasing physical activity levels in primary school physical education: The SHARP Principles Model.
Preventive Medicine Reports, 3, 7-13. https://doi. org/10.1016/j.pmedr.2015.11.007

Reynolds, C. R., \& Richmond, B. O. (1994). Revised children's manifest anxiety scale. Los Angeles, CA: Western Psychological Services.

Strauss, R., S., Rodzilsky, D., Burack, G., \& Colin, M. (2001). Psychosocial correlates of physical activity in healthy children. Archives of Pediatrics and Adolescent Medicine, 155(8), 897-902.

Ströhle, A. (2009). Physical activity, exercise, depression and anxiety disorders. Journal of Neural Transmission, 116, 777-783. https://doi.org/10.1007/s00702-008-0092-x Stubbs, B., Koyanagi, A., Hallgren, M., Firth, J., Richards, J., Schuch, F., ... Vancampfort, D. (2017). Physical activity and anxiety: A perspective from the World Health Survey. Journal of Affective Disorders, 208, 545-552. https://doi.org/10.1016/j.jad.2016.10.028

Weiss, M. R. (2012). Teach the children well: A holistic approach to developing psychosocial and behavioral competencies through physical education. Quest, 63, 55-65. doi: 10.1080/00336297.2011.10483663

Yoo, Y. G., Lee, D. J., Lee, I. S., Shin, N., Park, J. Y., Yoon, M. R., \& Yu, B. (2016).The effects of mind subtraction meditation on depression, social anxiety, aggression, and salivary cortisol levels of elementary school children in South Korea. Journal of Pediatric Nursing, 31(3), 185-197.
Corresponding author Irina Klizienė Institute of Social Sciences, Arts and Humanities Kaunas University of Technology Donelaičio str. 73, Kaunas 44239 Lithuania Tel. +37068239370 Emailirina.kliziene@ktu.lt 